\title{
Vocabulario del delito contra el patrimonio
}

\author{
Vocabulary of crime against heritage
}

Consuelo Meza Lagos ${ }^{1}$

\begin{abstract}
RESUMEN
Los delincuentes han multiplicado las modalidades de robo en muchas esferas de nuestra sociedad peruana. El primero en reflejar esta situación es nuestro léxico, quien presenta un incremento trascendente en los últimos tiempos. El aporte de estas nuevas voces no proviene solo del mundo delincuencial, sino también de las fuerzas del orden, quienes para identificar cada modalidad han recurrido a la creación de un léxico muy variado, tanto para identificar el tipo de robo como al delincuente que lo ejecuta. En algunos casos, una voz ha sido reemplazada por otra por considerarse más precisa, y en otros casos se ha incrementado la lista para puntualizar el delito. En este artículo, presentamos el léxico de las diferentes modalidades de delito contra el patrimonio, distribuido en campos semánticos como son el sistema bancario (subcampos de tarjetas de crédito, cajeros automáticos), los robos en casas (subcampo modalidad de ingreso a la casa con fractura o sin fractura de puertas), robos de vehículos, robo a peatones (subcampo con armas o sin ellas) y robos a centros comerciales.
\end{abstract}

\section{Palabras clave}

Campo semántico, subcampo semántico, léxico, hurto, robo.

\begin{abstract}
Criminals have multiplied the theft patterns in many areas of our Peruvian society. The first to reflect such situation is our lexicon, which gives a significant increase in recent times. The contribution of these new voices does not only come from the criminal world, but also from the forces of order, who to identify each modality have turned to the creation of a very varied lexicon, both to identify the type of robbery and the offender who executes it. In some cases, one voice has been replaced by another since it is considered more accurate; in other cases the list has been increased to specify the crime. In the present article, we introduce the lexicon of the different types of crime against heritage; distributed in semantic areas such as the banking system (credit card subfields, ATMs), house burglaries (sub-mode of entry to the house with Fracture or without door breaking), vehicle theft, pedestrian theft (subfield with or without weapons) and robberies to shopping centers.
\end{abstract}

\section{Keywords}

Semantic field, semantic sub - area, lexicon, robbery, theft.

\section{INTRODUCCIÓN}

En los últimos tiempos, nuestra sociedad se ha visto invadida por una serie de acciones delictivas que se han ido incrementando con el pasar de los años. Los ladrones y delincuentes son día a día parte de las noticias de portada.
Cada vez más refinados o brutales, recurren a muchas maneras de cometer delitos contra el patrimonio. Estas, a través del tiempo, se han incrementado en diferentes modalidades, cada vez más especializadas, convirtiéndose en una verdadera lista que puede ir clasificándose en campos semánticos y estos a su vez en

Licenciada en Educación, especialista en Lingüística Hispánica y Didáctica de la Comunicación Secundaria, con maestría en Lingüística. Es docente universitaria y de otros centros de estudio. Es autora de diversos artículos de investigación lexicográfica y realiza investigación en el campo de la lingüística. 
subcampos semánticos. Así, por ejemplo, los ladrones de casa han encontrado diferentes modalidades para ingresar a ella, pero también han encontrado una forma de actuar cuando están ya dentro de ella, con dueños de casa ausentes o presentes. Lo mismo pasa cuando se trata de apropiarse de un auto, pues existen muchas formas de nombrar al delito cuando se trata de la forma como ha sido sustraído el vehículo. No podemos dejar pasar los delitos cometidos en los centros bancarios, pues existe una variopinta organización del hampa que ha generado nuevo léxico para determinarlos.

Conviene hacer una revisión del significado de "delito". En el DRAE, la entrada delito, en su acepción 3, dice: Der. Acción u omisión voluntaria o imprudente penada por la ley. Para el Código Penal de las leyes peruanas, se considera delito a la omisión dolosa o culposa penada por ley (Título II Del hecho punible, Cap. I Bases de la punibilidad). Es importante anotar que existen diferentes tipos de delitos, tales como delitos contra el pudor y las buenas costumbres, delito contra la vida, el cuerpo y la salud, delitos contra la familia, delitos contra la libertad, contra los derechos intelectuales, etc. Este trabajo versa expresamente en el delito contra el patrimonio, es decir, aquellas acciones que van en contra de la pertenencia de un bien, tales como hurto, robo, abigeato, apropiación ilícita, estafa, delitos informáticos, entre otros.

Como se sabe, los delincuentes emplean un lenguaje encriptado al denominar sus delitos, con el propósito de no ser entendidos por las personas que no están involucradas en sus actividades delictivas. La necesidad de evadir a los policías es una razón más poderosa para emplear este lenguaje. Sin embargo, este léxico no se queda solo en este grupo, sino que abarca otras esferas de nuestra sociedad, principalmente el popular, convirtiéndose en parte de nuestro léxico, pues encuentra una forma de difundirse, a través de los medios de comunicación, como señala Lovón (2014). Palabras como burra o patuca por 'vehículo policial', grifo por 'marihuana', registradas por Arana (2008), son muestra de cómo estas pueden pasar a formar parte de nuestro léxico popular.
Peroċquiénesson losque se encargan de tipificar estos delitos al momento de ser clasificados como tales? En realidad, son las fuerzas del orden quienes han recurrido a la creación de un léxico muy variado, tanto para identificar el tipo de robo como al delincuente que lo ejecuta. Los delitos han ido incrementándose notablemente y para hacer los partes policiales, de alguna manera había que nombrarlos. Los policías les dan nombres en razón a algún hecho o referencia del delincuente. Los "alias", por ejemplo, son puestos por la policía con el propósito de identificarlos, del mismo modo otorga nombres a las bandas. Así por ejemplo, "Los Evangélicos" es una banda dedicada al robo y desmantelamiento de autopartes de vehículos menores, tales como motos lineales y mototaxis; la banda fue llamada así porque uno de sus integrantes tiene un pariente que pertenece a esta organización religiosa.

Los delitos también son tipificados, nombrados por los policías, para hacer más precisa la labor del denunciante. Han nacido palabras, por mencionar algunas, como "carterista", para denominar al ladrón que roba carteras; "cogotear" para describir la acción de tomar por el cuello a la víctima y proceder al robo; de allí deriva "cogotero" para denominar al ladrón que ejecuta el robo en esa modalidad. No es difícil imaginar por qué el policía da el nombre al delito y lo tipifica. El léxico se ve incrementado por el accionar del delito y por denominación de la policía, que al presentar al delincuente o a las bandas de delincuentes ante los medios de comunicación, hace que la ciudadanía tome conciencia de estas formas de delito y las asuma luego como parte de su léxico. Entonces, no es solo un léxico aislado, del medio delincuencial, sino que involucra a toda la ciudadanía.

En las memorias anuales, las fuerzas policiales hacen un recuento de los delitos más recurrentes. Presentan un listado con el que los abogados, jueces y fiscales hacen referencia del delito. Esto con la finalidad de unificar criterios y actualizar sus datos. Seguidamente, el ciudadano conoce la tipificación y al hacer la denuncia emplea este léxico que pasa a formar parte de su repertorio. Entre ellos tenemos: raqueteo, tendeo, el sueño, la barbie, caballo 
de Troya, rififi, bujiazo, la visita, escupitajo, cascada, entre otros tantos que expondremos líneas abajo. Cierto es que las modalidades mutan constantemente; sin embargo, algunos delitos son recurrentes y por ello se quedan como aporte a nuestro léxico.

\section{MATERIAL Y METODOLOGÍA}

Para la realización de este trabajo de investigación, se ha procedido a recolectar información léxica de los periódicos de circulación nacional y local, además de las publicaciones de las páginas web de Internet. También se ha procedido con la revisión de atestados e informes policiales, así como sentencias judiciales que dan fe del uso del léxico presentado.

En relación con las entradas, se ha optado por definir solo aquellas que son recurrentes en nuestro medio; esto quiere decir que el uso es el factor determinante para una definición, antes que la etimología o la sucesiva lexicalización de una forma y luego de otra. Por ello, las remisiones obedecen a este criterio; el uso, pues se remite a las entradas de uso recurrente.

También se ha tenido en cuenta la tipificación que hacen las autoridades, jueces y fiscales en relación a qué es un robo y qué es un hurto. Entiéndase por robo al delito que comete el delincuente al apoderarse con ánimo de lucro y con violencia o intimidación; mientras que el hurto es el delito que, al igual que el robo tiene ánimo de lucro, pero no existe la intimidación ni violencia; esto significa que la víctima se sorprende al darse cuenta de la falta de su pertenencia.

Se ha empleado solo la marca gramatical y no la marca de uso, debido a que esta no proviene del mundo del hampa, sino de las fuerzas policiales o responsables de la seguridad de los bancos para nominarlas, y que ha pasado a nuestros diarios y medios de comunicación masiva.

Para presentar las entradas, se ha preferido organizarlas en campos semánticos seguidos de subcampos semánticos, para su mejor entendimiento y para relacionar mejor los conceptos. Se han empleado ejemplos de uso para testimoniar el empleo de este léxico en nuestra sociedad, tanto de Internet, de periódicos, así como de entrevistas a las fuerzas del orden.

\section{LOS CAMPOS SEMÁNTICOS}

El campo delincuencial es amplio, los delitos campean en cualquier esfera de nuestra sociedad. Para hacer más didáctica esta investigación, se ha preferido organizar el léxico en campos semánticos.

Cuando las palabras están relacionadas en su significado esencial se pueden agrupar en los llamados campos semánticos. Estos son un conjunto de palabras que comparten un significado esencial. Así, el campo semántico de los útiles escolares estará conformado por regla, cartuchera, lápiz, colores, cuadernos... Sin embargo, estos campos pueden ser tan amplios que a su vez se pueden dividir en subcampos; por ejemplo, si hablamos de colores, tendremos el subcampo de amarillo y toda su gama, del rojo y toda su gama, y así sucesivamente.

En el campo semántico de la delincuencia, los delitos son amplios, como se evidenció líneas arriba. Para este trabajo, se delimitará en el campo semántico de delitos contra el patrimonio tales como el robo de casas, robos de vehículos, robos en centros comerciales, asaltos a los peatones, robos de tarjetas de crédito, y los subcampos semánticos respectivos. Por otro lado, se presentará solo el delito, mas no a la persona que ejecuta el delito; por ejemplo, definiremos a la "monra", mas no al "monrero". Tampoco presentaremos en el listado entradas que son predecibles, como es el caso de delitos de robo agravado como el "robaluz", "robaagua", "robacable" o "robavoto", entre otros.

\section{ANÁLISIS LEXICOGRÁFICO}

En este apartado, se presentan y se definen las entradas lexicográficas del vocabulario del delito contra el patrimonio de acuerdo a una serie de campos semánticos. 


\subsection{Campo semántico: Robo de viviendas}

\subsubsection{Subcampo: Robo sin fractura de puertas o ambientes de la casa}

caballo de Troya. loc. sust. Modalidad de robo que consiste en visitar una vivienda con el pretexto de estar interesado en el producto que ofrece en venta el propietario. 2. Estudio que realizan los ladrones sobre las costumbres, horarios y cantidad de personas de una vivienda, para luego robar.

Esta modalidad de robo se llama 'Caballo de Troya', porque primero ingresan los ladrones, como el caballo, para estudiar la casa, ver qué poseen y analizar los posibles ingresos para un robo" (http://bit.ly/2flay2P del 18 febrero 2014).

La delincuencia usa como principal modalidad la conocida como 'Caballo de Troya'. Esta consiste en infiltrar a sus cómplices dentro del departamento que piensan desvalijar o del mismo edificio, como por ejemplo servidumbre o personal de seguridad, para que estos les brinden la información de todos los movimientos de los residentes (http:// bit.ly/2g22ydG del 12 septiembre 2010)

cordelero. m. Modalidad de hurto de prendas de vestir lavadas, que se hallan colgadas en los cordeles de las azoteas.

Cordelero.- Es el hurto de prendas de vestir lavadas que se hallan colgadas para efectos de su secado (PNP 2012: $404)^{2}$.

el sueño. loc. sust. Modalidad de robo en un domicilio, en horas de la madrugada, mediante un somnífero que se pone a las víctimas.

Otro método que emplean es el 'sueño'. Aprovechan entre las 2 y 4 de la madrugada para entrar a una vivienda usando spray con somníferos
(http://bit.ly/2aWBGhW del 04 noviembre 2012).

empujonazo. m. V. la visita.

Luego de ingresar a una vivienda con la modalidad del 'empujonazo', tres 'robacasas' fueron capturados por la policía (http://bit.ly/2g23Ipu 7 julio 2014).

escalamiento. m. Modalidad en la que el delincuente entra a robar subiendo por las paredes o muros de las viviendas, mediante la agilidad $\mathrm{u}$ otros medios.

Los hampones utilizaron la modalidad del 'escalamiento', es decir, treparon la pared de una casa contigua al edificio (http://bit. ly/2gFAG00 del 23 marzo 2014).

escape a (de) domicilio. loc. sust. $m$. Modalidad de robo rápida y sorpresiva en la que el delincuente ingresa a una casa cuyo propietario dejó abierta la puerta momentáneamente para realizar alguna actividad fuera de ella.

El escape a domicilio. Se realiza cuando el delincuente ingresa a un domicilio o local comercial, cuyo propietario dejó abierta la puerta, apoderándose de un bien (http://bit. $\mathrm{ly} / 2 \mathrm{fR} 7 \mathrm{tR} 4)$

estuche. $m$. En ausencia de los propietarios: Modalidad de robo ejecutada con una llave maestra o ganzúa que se emplea para abrir las puertas de los domicilios.

Estuche.- En esta modalidad se utiliza una llave duplicada de la chapa del inmueble o una llave maestra o ganzúa, para luego ingresar (Corte Superior de Justicia de Lima 2010: 5).

la barbie. loc. sust. En ausencia de los propietarios: Modalidad de robo en que se

Pérez Guadalupe (2000) registra cordelero, que es el ladrón que ejecuta el robo y cordelear que es la acción de robar las prendas de vestir tendidas. 
emplea una mujer atractiva para distraer a los vigilantes de las viviendas.

La barbie: Utilizan a guapas chicas para distraer a seguridad. (http://bit. ly/2g73qOs del 10 febrero 2014).

la visita. loc. sust. Modalidad en que el delincuente llama a la puerta como si fuera una persona conocida y ante un descuido del propietario ingresa violentamente para robar.

Si un desconocido toca su timbre, no salga de inmediato. Pregunte primero quién es y qué desea, pues cámaras de seguridad han captado que esta es una nueva modalidad de robo, bautizada como 'La visita' (http://bit. ly/2gVAMDO del 26 enero 2014).

pintado. m. Para obtener la conveniencia de robar y delimitar su zona: Modalidad de robo que consiste en marcar la pared de una casa que los delincuentes han vigilado varios días.

Modalidad del sticker o pintado, dejan una marca de advertencia (http://bit. ly/2g6Zs8e).

silicona. f. Modalidad de robo que consiste en colocar silicona o plastilina en las ranuras de las chapas de las puertas, con la finalidad de bloquear su sistema de seguridad y abrirlas con cualquier llave.

Un tercer método frecuente es el de la silicona, en el que meten esta sustancia o plastilina por la ranura de las chapas de las puertas, a fin de bloquear los pines y poder abrirlas con cualquier llave. (http://bit.ly/2g72Fot del 01 febrero 2014).

\subsubsection{Subcampo: Robo con fractura de puertas o ambientes de la casa}

cizalla. f. Modalidad de robo en que se rompe candados, cadenas o barrotes empleando una herramienta de metal como tijera.

También existe la cizalla, que es diferente a la monra, pues en este caso, se cortan los barrotes con ayuda de una tijera que lleva ese nombre, cizalla (PNP: 19 junio 2014).

culatazo. $m$. Robo que consiste en atar con una soga o cadena la culata de un vehículo con la cerradura de la puerta de una casa o dispensador, para luego tirar de ella con velocidad. 2. Robo consistente en emplear parachoques fuertes para impactar adrede al vehículo de la víctima con la finalidad de frenar su avance.

También es común el "jalonazo" o "culatazo", en el que se arrancan las puertas -literalmente- atándolas con una soga al parachoques de un vehículo. (http://bit.ly/2aZgQug del 26 julio 2013).

Ahora encontramos el robo que se llama "culatazo" que se realiza entre varios delincuentes junto con el uso de camionetas y autos con parachoques fuertes para así impactar a su víctima sin perjudicarse o también utilizando una soga para lograr abrir alguna vivienda ${ }^{1}$ (sites. google.com del 2014).

fierreo. m. V. monra.

Romper las puertas con pata de cabra $u$ otra herramienta es una de las modalidades más extendidas de 'fierreo', pero el hampa sigue con atención las tecnologías de seguridad para adaptarse a ellas (http://bit. ly/2fRt9tg del 24 diciembre 2010).

forado. m. Modalidad de robo que consiste en perforar la pared con herramientas de construcción como cinceles, martillos, entre otros.

Surquillo: Roban local de Inkafarma con modalidad del forado. Los delincuentes ingresaron por un orificio de aproximadamente un diámetro que cavaron desde un inmueble contiguo a la farmacia (http://bit.ly/2h10KWF del 23 julio 2013). 
gatazo. m. Modalidad de robo en la que se fuerza una puerta con una gata, con la finalidad de ingresar a la casa y proceder al robo.

Modalidad gatazo: vista fotográfica en donde se aprecia a una persona colocando una gata hidráulica bajo una puerta metálica de un establecimiento comercial (es.scribid.com del 2009).

jalonazo. m. Modalidad de robo consistente en arrancar una puerta o dispensador con ayuda de una cadena unida a la parte posterior de un vehículo.

Delincuentes emplean cadenas $y$ vehículos para arrancar dispensadores de dinero de sus bases. El 'jalonazo', modalidad empleada en Chile y en Colombia, se viene extendiendo en nuestra capital (http://bit.ly/2gSy5yU del 04 julio 2013).

monra. m. Modalidad de robo a una casa con ayuda de una barra de acero con punta biselada o algo similar para palanquear $y$ romper puertas y ventanas.

La modalidad de la "monra" practicada de preferencia en zonas residenciales, consiste en ingresar a una vivienda aprovechando la ausencia de los dueños de casa (...), provistos de patas de cabra, ganzúas y corta barrotes; los delincuentes se llevan hasta los sanitarios (http://bit.ly/2gFY8du del 2014). ${ }^{3}$

pulpo. $m$. $V$. ventosa.

Otra modalidad es el "Pulpo": los ladrones colocan un chupón de jebe en el vidrio de la puerta, lo cortan con diamante y abren el seguro (http:// bit.ly/2aWBGhW del 4 noviembre de 2012).

tijera. $f$. V. cizalla.

La cizalla también es conocida como tijera. La modalidad de robo puede llamarse también la modalidad de la tijera (PNP: 19 junio de 2014).

ventosa. $f$. Modalidad de robo que consiste en emplear un chupón de jebe que se coloca al vidrio de la ventana cercano al seguro para romperlo con un cortador de vidrios.

'Ventosa': esperan que todos hayan salido de la casa, luego colocan un desatorador de jebe, usados en los servicios higiénicos, en una ventana cercana a la puerta y con un diamante cortan el vidrio, haciendo un orificio por donde abren el seguro e ingresan (http://bit.ly/2gSzaGY 18 diciembre 2011).

vitrovén. (De Vitrovent, marca registrada) $\mathrm{m}$. Modalidad de robo usada para ingresar a las casas, rompiendo las ventanas hechas con marco de aluminio.

Aveces por falta de conciencia de seguridad, ponen en las entradas de sus casas esas ventanas vitrovén sin preocuparse en que son fáciles de romper. Esa modalidad es el vitrovén (PNP: 28 junio 2014)

\subsection{Campo semántico: Robo de vehículos}

bujiazo. $m$. Contra autos detenidos o en marcha, en los semáforos o cruces: Modalidad de robo que consiste en frotar el terminal de una bujía para calentarla y luego lanzarla a las lunas de autos para apoderarse de objetos de los pasajeros.

El semáforo en rojo y la congestión vehicular son los principales aliados de los ladrones que operan en la avenida Angamos en Surquillo bajo la modalidad de "Bujiazo" (http://bit. ly/2fYpzRm del 30 septiembre 2012).

escorpión. m. Entre dos o más ladrones, a los vehículos: Robo en el que un ladrón distrae al

\footnotetext{
La llamada "monra" existe muchos años atrás, antes que su reciente sinónimo "fierreo". Sin embargo, "fierreo" no es tan popular como sigue siendo la "monra".
} 
conductor, mientras que el otro sustrae objetos de valor de la parte posterior o del copiloto.

Otra modalidad es la conocida como el 'escorpión', que consiste en que un sujeto distrae al conductor de un auto mientras que otro abre el asiento del copiloto y sustrae sus pertenencias (http://bit.ly/2fMzfjv del 21 mayo 2013).

patinaje. $m$. En los cruces de carretera: Modalidad de asalto que consiste en trepar al vuelo un vehículo de carga.

La policía capturó a uno de los miembros de la banda que utilizaba la modalidad del "patinaje" para asaltar y robar camiones (http://bit. ly/2gSDaqN del 27 julio 2013).

tablazo. m. Modalidad de robo que consiste en dejar palos y fierros en la pista para detener un vehículo y despojar de sus pertenencias a los pasajeros.

Una nueva modalidad de robo está siendo utilizada por los delincuentes en las principales avenidas de lima: El Tablazo. Esta técnica consiste en colocar palos y piedras en la carretera para que los vehículos frenen y puedan robarle todas sus pertenencias (http:// bit.ly/2bd67eA del 2 de noviembre de 2013).

vitroca. f. Modalidad de robo de un auto que consiste en emplear como llave una ganzúa para abrir la puerta.

Agentes de la Comisaria de El Tambo lograron capturar a dos sujetos presuntos integrantes de la banda autodenominada "Los Vitrocas del Tambo", los mismos que vendrían perpetuando robos de autopartes en modalidad vitroca en Huancayo (http://bit.ly/2fYtk9c del 11 diciembre 2013)

\subsection{Campo semántico: robo a peatones}

\subsubsection{Subcampo semántico: Asalto a mano armada}

raqueteo. $\mathrm{m}$. Modalidad de asalto a mano armada, que consiste en reducir al peatón para despojarlo de sus pertenencias y huir en el auto que les sirvió para seguirlo.

La Policía Nacional capturó en San Miguel a tres delincuentes que operaban bajo la modalidad del 'raqueteo' a bordo de un auto, luego de haber asaltado a una mujer en las inmediaciones de la cuadra 12 de la avenida Lima (http://bit.ly/2gMKlEH del 12 enero 2014). ${ }^{4}$

\subsubsection{Subcampo semántico: Asalto con o sin armas}

amigo elegido. loc. sust. Víctima elegida por delincuentes para entregarle un supuesto regalo, y al entrar en contacto con la persona, proceden a reducirla.

Las modalidades son cada vez más osadas y la más usada en estos días es la del 'Amigo elegido', en donde el ladrón llega con un regalo para la víctima y cuando logran tener contacto con ella la reducen (www. frecuencialatina.com del 5 noviembre 2013)

arañita. f. Modalidad de asalto mediante la cual el delincuente se sube al techo del mototaxi. 2. Modalidad de asalto a un transeúnte quien es sorprendido por un delincuente que luego huye en mototaxi.

Esta modalidad de robo se conoce en Piura como la 'arañita' pues el delincuente se sube al techo de la mototaxi como el hombre araña $y$ obliga al chofer a reducir la velocidad (http://bit.ly/2fRBUmS del 16 enero 2014)

En los diarios y medios de comunicación masiva, se registra la palabra que describe a la persona que realiza la acción (el raquetero) y la acción de cometer el delito (raquetear). 
Últimamente se está empleando la modalidad de "la arañita", en la que tres forajidos emplean una mototaxi para buscar y seleccionar a su víctima (http://bit.ly/2btNnJ7 del 26 marzo 2013).

bolero. m. Modalidad de robo en la que se despoja hasta de sus prendas de vestir a los borrachos que se quedan dormidos.

Otra forma es "el bolero", en donde los maleantes le roban hasta los zapatos a los borrachos que se quedan dormidos en la calle (http:// bit.ly/2btNnJ7 del 26 marzo 2013).

cascada. f. En la vía pública de poca concurrencia de público: Modalidad de robo consistente en dejar en el suelo un paquete que simula ser un fajo de billetes, y cuando la víctima lo recoge, aparece el supuesto dueño que propone cambiarlo por algo de valor.

Recuerdo que cuando recién terminé el colegio, a la salida de la academia, me quisieron hacer la cascada con un paquete de dinero que supuestamente se cayó a mi lado, pero como estaba misio me quisieron quitar las zapatillas (http://bit.ly/2fRFdut del 1 agosto 2009).

cogoteo. m. Modalidad de asalto que consiste en tomar a la víctima por la espalda y sujetarla por el cuello, presionando muy fuertemente para inmovilizarla.

El "cogoteo" es una modalidad de asalto que consiste en que el delincuente sujeta a su víctima por atrás colocando fuertemente el brazo alrededor de su cuello, impidiendo que se mueva (http://bit.ly/2gsBVBP del 28 octubre 2013). ${ }^{5}$ escape. $\mathrm{m}$. Modalidad de robo rápida y silenciosa, con fuga inmediata del delincuente.

Aprovechando que ambas mujeres se encontraban charlando, un delincuente utilizó la "modalidad del escape " para robar una cartera con cinco mil nuevos soles en Chimbote (http:// bit.ly/2fRBFs4 del 22 noviembre 2012). ${ }^{6}$

escupitajo. m. Modalidad de robo que consiste en escupir a la víctima para distraerla $y$ robarle sus pertenencias.

El septuagenario fue sorprendido por un grupo de tres féminas, quienes le escupieron y este, al atender dicha agresión, no se dio cuenta que le sacaron su celular por la espalda. Esta modalidad del escupitajo es uno de los muchos de las modalidades de robo (www.elcorreodeprietto.com del 30 noviembre 2013).

gateo. m. Modalidad de robo de meretrices $\mathrm{u}$ homosexuales que consiste en apropiarse del dinero del cliente mientras este se encuentra distraído.

Después del encuentro sexual con la meretriz a las 4:00 am, en un hotel cercano, Irvan Cavero se percató que había sido víctima del robo de su billetera con 120 soles, bajo la modalidad del "gateo", que consiste en que mientras el agraviado está distraído su cómplice con su brazo alcanza el objeto a robar (http://bit.ly/2gMO2u8 del 30 octubre 2010).

pepeo. $\mathrm{m}$. Modalidad de robo que consiste en drogar a una persona con sicofármacos colocados de manera disimulada en sus bebidas.

También se registra cogotear como la acción que ejecuta el delito; cogotero, como el ladrón que procede a robar bajo esa modalidad. Es conocido también como el pescueceo, y la acción como pescuecear.

6 También "escapista y "escapear". 
Luego de su detención en la noche del viernes último las autoridades tipificaron el delito contra el patrimonio, robo de vehículos en la modalidad de pepeo, le encontraron en posesión de cinco pastillas de colores celeste, verde y rosado. Estas pastillas las habría utilizado para pepear y dormir a sus víctimas (http://bit.ly/2h19pIO del 10 julio 2014).

rapiña. V. Hurto que se comete aprovechando la desesperación de víctimas de siniestros o catástrofes.

Manifiesta que se le imputó la comisión de actos dolosos (robo calificado en la modalidad de pillaje o rapiña); que fue absuelto en el proceso penal que se le instauró; que se han vulnerado sus derechos al trabajo (...), puesto que al expedirse las resoluciones cuestionadas no se tuvo en cuenta la sentencia penal absolutoria (http://bit.ly/2gezm3z del 23 octubre 2006$)$.

maquinazo. m. Entre dos delincuentes: Modalidad de robo mediante la cual un delincuente empuja a su víctima, le extrae el dinero del bolsillo y se da a la fuga raudamente, mientras que el otro obstaculiza a la víctima para evitar que persiga a su cómplice.

Maquinazo.- Consiste en la sustracción de dinero de los bolsillos del pantalón del agraviado, para lo cual el autor empuja con una de las manos a la víctima, introduciendo rápidamente la otra mano en el bolsillo del pantalón para sustraerle el dinero o billetera, emprendiendo de inmediato la fuga; para evitar la persecución del agraviado, el cómplice obstaculiza a la víctima permitiendo la fuga del autor. Esta modalidad se comete mayormente en lugares de afluencia de público (http://bit. ly/2gsKoF3 del 6 junio 2011).

\subsection{Campo semántico: Robos en centros comerciales}

anzuelo. m. En tiendas o centros comerciales: Modalidad de robo consistente en emplear como gancho un alambre con punta en forma de U para violentar vitrinas donde se exhiben los productos.

También está el anzuelo, que consiste en utilizar un alambre o carrizo con un extremo en forma de $U$, a fin de violentar vitrinas entreabiertas (http:// bit.ly/2g72Fot del 1 febrero 2014).

cajoneo. m. $<$ En tiendas $\mathrm{O}$ centros comerciales $>$ Modalidad de robo ejecutada entre dos delincuentes en la que uno induce a la cajera a dejar su lugar para atenderlo, mientras que su cómplice roba el dinero de la caja.

Losladrones actuaron bajola modalidad del cajoneo, que consiste en cerrar el paso colando un camión adelante que poco a poco va deteniendo la velocidad y otro camión al costado para que el vehículo a ser asaltado no pueda cambiar de vía (http://bit.ly/2gsLIrv del 9 abril 2009).

rififi. $\mathrm{m}$. Modalidad de robo que consiste en hacer un forado en el techo del local para descender mediante sogas o trapos.

Los pillos también intentaron llegar hasta las bóvedas de seguridad de la tienda de cambio (...), sin contar con el sistema de seguridad. "Los delincuentes reactualizan la modalidad 'Rififi' de 1950. Ya son muchos casos, dijo un PNP” (http://bit.ly/2fROW3R del 9 junio 2007).

tendeo. m. En los centros comerciales: Modalidad de robo que consiste en que el ladrón sustrae objetos o prendas que pueden esconderse dentro de su ropa holgada o que simula embarazo, en el caso de mujeres.

Se trata de Ronald Q., natural de Sicuani, Luzmila S. (35) y Mariluz P. (32), las dos últimas, procedentes de Cusco del distrito de Santiago, quienes abordo de un vehículo, robaban las tiendas comerciales bajo la modalidad del tendeo (http://bit.ly/2h19fRz del 30 agosto 2011). 
4.5. Campo semántico: Robos en la banca

\subsubsection{Subcampo: robo de tarjetas de crédito}

cambiazo. m. Modalidad de robo que consiste en cambiar al descuido la tarjeta de crédito de una persona con el pretexto de ayudarla en un cajero automático o al pagar con tarjeta.

Este fin de semana en "El Dominical de Panamericana" vea un informe exclusivo sobre el "Cambiazo", una modalidad de robo creciente en los cajeros automáticos (http://bit. ly/2gsHCzA del 25 noviembre 2011).

Nota: "Cambiazo" a su vez presenta dos modalidades:

a) encontronazo. m. En cajero automático, provocando la distracción de la víctima: Modalidad de robo que consiste en sacar una tarjeta de la ranura del cajero y reemplazarla por otra.

El encontronazo: Ojean sobre el hombro de sus víctimas cuando estas ingresan sus contraseñas en el cajero automático. Tiran monedas al piso para distraerlas y realizan el "cambiazo" de tarjetas (http://bit.ly/2fRJY7j del 6 diciembre 2012).

b) franelazo. m. Generalmente en cajeros automáticos que han sido previamente adulterados: Modalidad de robo en la que la tarjeta de la víctima no se introduce en la ranura del cajero y el delincuente se ofrece a limpiarla con su ropa, cambiándola rápidamente por otra.

La segunda modalidad es el 'franelazo'. Los hampones colocan un dispositivo en el cajero para que la tarjeta del usuario se atraque. Luego, le ofrece ayuda al usuario y aprovecha este lapso para cambiar la tarjeta rápidamente (peru21.pe del 13 octubre 2009). cintillo. m. Modalidad de robo que consiste en poner una cinta magnética disimulada en la ranura del cajero automático para retener la tarjeta de crédito.

Entre las modalidades de estafa destacan los cintillos en los cajeros automáticos. Este sistema consiste en la colocación de un plástico que se adhiere a la ranura de un cajero automático. El mecanismo del cintillo hace que la tarjeta de crédito quede retenida tras digitar la clave (http://bit. ly/2fYE1sJ del 11 agosto 2007).

skimmer. m. V. clonación.

La clonación es igualmente una de las modalidades más populares. También es llamada skimmer debido al aparato usado para copiar la clave e información que tiene la tarjeta en su banda magnética. Luego de copiar la información, esta es vaciada a una computadora y de ahí puede pasarse a otra tarjeta (http://bit.ly/2fYE1sJ del 11 agosto 2007)

\subsubsection{Subcampo: Robo en cajeros automáticos}

clonación. f. En tarjetas de débito o crédito: Modalidad de robo en que se emplea un dispositivo colocado en el cajero automático, que copia toda la información de la tarjeta, para ser descargada a una computadora y desde allí pasar el dinero de una cuenta a otra.

En el Perú, una de las modalidades de fraude bancario más comunes es la clonación de las tarjetas de crédito. El delincuente puede extraer todo el dinero de la cuenta de su víctima sin que esta se dé cuenta de inmediato (http://bit. ly/2fYG1kB del 30 agosto 2012).

lazo libanés. loc. sust. V. cintillo.

Otra es la del lazo libanés o cintillo.

En este caso, los hampones colocan una liga con una fibra plastificada en la ranura para retener la tarjeta. Antes han 
puesto unas indicaciones para que el cliente digite tres veces su clave secreta $y$ denuncie al banco la retención de la tarjeta (http://bit.ly/2fRSl2B del 14 octubre 2009).

\section{CONCLUSIONES}

Las modalidades de robo cambian constantemente, lo que genera el nacimiento de nuevo léxico para tipificarlas. La Policía Nacional se encarga de darles un nombre, pero esto sería una anarquía si no existiese un consenso entre sus pares, por lo cual, en sus informes anuales van codificando su tecnolecto en una especie de vocabulario impreso de uso interno, que llega a nosotros, los ciudadanos de a pie, por los medios de comunicación. $\mathrm{Y}$ nosotros las acogemos como parte de nuestro uso.

Como se aprecia en los subcampos, las modalidades de delitos contra el patrimonio son numerosísimas y su formalización léxica depende de las sutilezas que tenga cada una para diferenciarse de otras.

También se observa que existen delitos tan comunes en el mundo del hampa que pasan a nuestro léxico como un préstamo o en forma íntegra en su significado. Es el caso de "rififi" (derivado del nombre de una antigua película francesa), de "ventosa", que en Bolivia es nuestro equivalente a "forado", la "monra" (tan común en Chile), o los nombres de delito de la banca que se comparte en muchos países como es el "skimmer", poco conocida en el Perú, y denominada "clonación".

Los términos que designan delitos son cambiantes y se renuevan. Por ejemplo, para expresar el robo a casas fracturando la cerradura coexiste la voz "fierreo", relativamente reciente, con "monra", a la que podría reemplazar. Por otro lado, aparecen palabras nuevas, que ilustran cambios tecnológicos en el delito, como "cintillo" o "skimmer". 


\section{REFERENCIAS}

Álvarez, Juan (2009) Diccionario de peruanismos: el habla castellana del Perú. Lima: Universidad Alas Peruanas.

Bendezú, Guillermo (1975) Vocabulario hampesco. Ayacucho: Ed. Kuntur.

Arana, Paola (2010) La herencia léxica del hampa en el castellano actual limeño. Actas III Congreso de Lexicografía. Academia Peruana de la Lengua.

Hildebrandt, Martha (2013) Peruanismos. Edición actualizada y aumentada. Lima: Planeta.

Lovón, Marco (2014) El léxico del robo en el habla peruana. Garcés Gómez, María Pilar (editora). Léxico, historia y diccionarios. Universidade da Coruña.

Pérez, José Luis (2000) La construcción social de la realidad carcelaria. Lima: Fondo Editorial

Real Academia de la Lengua (2014) Diccionario de la lengua española. Vigésima tercera edición. Madrid: Espasa Calpe.

\section{REFERENCIAS ELECTRÓNICAS}

Arce, Álvaro (06 de diciembre de 2012) La mil y una estafas. Caretas.pe. Recuperado de http:// bit.ly/2fRJY7j

Asociación de bancos del Perú. (2013). Cambiazo de tarjeta en cajeros automáticos (ATM) y puntos de ventas. Disponible en internet. bit.ly/1r6rUrR Consultado el 22 de junio de 2014.

Cajeros automáticos son el nuevo blanco del hampa. (04 de julio de 2013) Recuperado de http:// bit.ly/2gSy5yU

Chicoma, P. (18 de febrero de 2014) Asaltan casas con "Caballo de Troya". Trome. Recuperado de http://bit.ly/2flay2P

Chimbote: delincuente roba 5 mil soles bajo la "modalidad del escape" (22 de noviembre de 2012) LaRepublica.pe. http://bit.ly/2fRBFs4

Chumo, P. (11 de agosto de 2007) Ladrones en la red (y en la calle). Laprimeradigital. Recuperado de http://bit.ly/2fYE1sJ

Chumpitaz, O. (04 de noviembre de 2012) Nuevas modalidades de los "robacasas" ponen en alerta a toda Lima. LaRepublica.pe. Recuperado de http://bit.ly/2aWBGhW

Comité Provincial de Segurdiad Ciudadana-COPROSEC (s.f) I Parte: delitos más frecuentes contra el patrimonio. Recuperado de http://bit.ly/2fR7tR4

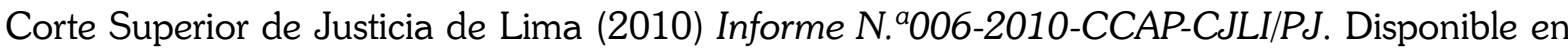
internet. bit.ly/1nArgxd. Consultado el 12 de junio de 2014.

Cuidado con el robo de placas: la nueva modalidad para asaltos (21 de mayo de 2013) Sitesgoogle. Recuperado de http://bit.ly/2fMzfjv 
Delincuentes asaltan bajo la modalidad del "Bujiazo" en Surquillo (30 de septiembre de 2012) Atv.pe. Recuperado de http://bit.ly/2fYpzRm

Detienen a dos sujetos por robo agravado de autopartes (11 de diciembre de 2013) Policiaperu. tumblr.com. Recuperado de http://bit.ly/2fYtk9c

Día de la madre: prevenga los robos (10 de mayo de 2013) LaRepública.pe. Recuperado de http://bit.ly/2g73qOs

El cogoteo puede ocasionar muerte por asfixia, para cardíaco o muerte cerebral (28 de octubre de 2013) Connuestroperu.com. Recuperado de http://bit.ly/2gsBVBP

Espinoza, R. (30 de octubre de 2010) Exreo mata meretriz por robarle billetera. Elpopular.pe. Recuperado de http://bit.ly/2gMO2u8

García, A. (9 de junio de 2007) Abren huecazo y pelan clínica. elPopular.pe. Recuperado de http:// bit.ly/2fROW3R

García, L. (14 de octubre de 2009) Usuarios de cajeros deben evitar a extraños a la hora de retirar dinero. Elcomercio.pe. Recuperado de http://bit.ly/2fRSl2B

Garreta, C. (12 de setiembre de 2010) Edificios, el nuevo blanco de los robos. LaRepublica.pe. Recuperado de http://bit.ly/2g22ydG

Gil. E. (23 de octubre de 2006) Sentencia del Tribunal Constitucional. Tc.gopb.pe. Recuperado de http://bit.ly/2gezm3z

Grau, J. (09 de abril de 2009) Seguridad ciudadana. Seguridadciudadana2009.blogspot.pe. Recuperado de http://bit.ly/2gsLIrv

Inseguridad ciudadana: Cuidado con el aumento de robos a casas. (21 de julio de 2016) Trome. Recuperado de http://bit.ly/2g6Zs8e

La Chira, R. Huaral: "Robacasas" fueron capturados por la policía. Trome. Recuperado de http://bit.ly/2g23Ipu

Lima: Robos a residencias aumentan en 30\% en céntricos distritos (23 de marzo de 2014) Peru21. Recuperado de http://bit.ly/2gFAG00

Manual de procedimientos operativos policiales (2012) Disponible en internet. bit. ly/1rjQozM. Consultado el 15 de junio de 2014.

Meléndez, J. (26 de julio de 2013) Fiestas patrias: Utilizan hasta seis modos de robar casas en feriados largos. La República.pe. Recuperado de http://bit.ly/2aZgQug

Modalidades de robo. (06 de junio de 2011). Tirodefensivoperu.com. Recuperado de http://bit. ly/2gsKoF3

Ortiz, César. (2014) ¿Sabe usted dónde está Lima cuadrada? Adonde.com. Recuperado de http:// bit.ly/2gFY8du

Paredes, T. (26 de enero de 2014) Cuidado con "la visita", nueva modalidad de robo. Trome. Recuperado de http://bit.ly/2gVAMDO 
¿Qué modalidades de robo y estafa conoces? (01 de agosto de 2009) Forosperu. Recuperado de http://bit.ly/2fRFdut

Rivas, J. (26 de marzo de 2013) Especies delictivas siguen más vigentes que nunca y a la caza de sus víctimas. LaRepublica.pe. Recuperado de http://bit.ly/2btNnJ7

Sánchez, F. (30 de agosto de 2012) Cómo evitar la clonación de tu tarjeta. Peru21. Recuperado de http://bit.ly/2fYG1kB

Sandoval, P. (01 de febrero de 2014) Robos a casas aumentan en Surco los fines de semana. ElComercio.pe. Recuperado de http://bit.ly/2g72Fot

San Miguel: Policía Nacional capturó a tres 'raqueteros' de 'Puerto Nuevo' (12 de enero de 2014) Peru21. Recuperado de http://bit.ly/2gMKlEH

Sequeiros, J. (30 de agosto de 2011) Caen "Los tenderos" de Calca, mientras huían. Diariocorreo. pe. Recuperado de http://bit.ly/2h19fRz

Surquillo: Roban local de Inkafarma con modalidad del forado (23 de julio de 2013) Peru21. Recuperado de http://bit.ly/2h10KWF

Torres, F. (25 de enero 2009) Seguridad ciudadana. Blogspot.pe. recuperado de http://bit.ly/2fRt9tg

Tribunal Constitucional del Perú (2006) Sentencia del tribunal constitucional. Disponible en internet. bit.ly/1wzFEv0. Consultado el 24 de junio de 2014.

Un policía mató a delincuente que intentó asaltarlo (16 de enero de 2014) Elcomercio.pe. Recuperado de http://bit.ly/2fRBUmS

Vallejos, R. (25 de noviembre de 2011) Aumentan robos por el "Cambiazo": Alerta en cajeros. Panamericana.pe. Recuperado de http://bit.ly/2gsHCzA

Fecha de recepción: 15-08-16

Fecha de aceptación: 10-11-16 